\title{
Confirmation of calibration capability of low-nominal capacity reference torque wrenches at NMIJ
}

\author{
Atsuhiro Nishino, Koji Ogushi and Kazunaga Ueda \\ National Metrology Institute of Japan, AIST, Tsukuba Central 3, 1-1-1 Umezono, Tsukuba, Ibaraki, 305-8563, Japan
}

\section{ABSTRACT}

The calibration procedure for a reference torque wrench (RTW), which is a torque transducer in the form of a torque wrench, is based on the JMIF-016 (TTSG-W102) technical guideline in Japan. The mounting position of an RTW is set to three directions $\left(0^{\circ}, 120^{\circ}\right.$, and $240^{\circ}$; case 1) when it is calibrated using dead weight torque standard machines (DWTSMs) with rated capacities of $1 \mathrm{kN} \cdot \mathrm{m}(1-\mathrm{kN} \cdot \mathrm{m}-$ DWTSM) and $20 \mathrm{kN} \cdot \mathrm{m}(20-\mathrm{kN} \cdot \mathrm{m}-\mathrm{DWTSM})$. However, the mounting position is set to three different directions $\left(0^{\circ}, 90^{\circ}\right.$ and $\left.270^{\circ} ; \mathrm{case} 2\right)$ when the 10-N.m-DWTSM is used. In this study, the effect of the difference of the RTW mounting position on the calibration results was investigated. Next, to confirm the equivalence of the RTW calibration capabilities of the 10-N.m-and 1-kN.m-DWTSMs, they were compared using two low-nominal capacity RTWs. The results obtained in cases 1 and 2 showed good agreement within the uncertainties. The recommended RTW calibration procedure is based on case 1 . But, if an RTW cannot be mounted in the $120^{\circ}$ and $240^{\circ}$ directions because of the space problem, case 2 can be adopted as the RTW calibration procedure. The RTW calibration capability of the $10-\mathrm{N} \cdot \mathrm{m}-\mathrm{DWTSM}$ was found to be equivalent to that of the $1-\mathrm{kN} \cdot \mathrm{m}-\mathrm{DWTSM}$ in the range of $5 \mathrm{~N} \cdot \mathrm{m}$ to $10 \mathrm{~N} \cdot \mathrm{m}$.

\section{Section: RESEARCH PAPER \\ Keywords: torque; low-nominal capacity; torque wrench; reference torque wrench; comparison}

Citation: Atsuhiro Nishino, Koji Ogushi and Kazunaga Ueda, Confirmation of calibration capability of low-nominal capacity reference torque wrenches at NMIJ, Acta IMEKO, vol. 6, no. 2, article 6, July 2017, identifier: IMEKO-ACTA-06 (2017)-02-06

Section Editor: Min-Seok Kim, Research Institute of Standards and Science, Korea

Received June 23, 2016; In final form May 6, 2017; Published July 2017

Copyright: (C) 2017 IMEKO. This is an open-access article distributed under the terms of the Creative Commons Attribution 3.0 License, which permits unrestricted use, distribution, and reproduction in any medium, provided the original author and source are credited

Corresponding author: Atsuhiro NISHINO, e-mail: a.nishino@aist.go.jp

\section{INTRODUCTION}

There are two routes in the torque traceability system in Japan, one for "pure torque" loading without any parasitic components and the other for "torque wrench" loading with an inevitable transverse force and bending moment. Figure 1 shows the SI traceability system of torque used in Japan [1], which was proposed by the National Metrology Institute of Japan (NMIJ) in cooperation with the Japanese industry. The reference standards for pure torque and torque wrench in firstgrade accredited laboratories are torque measuring devices (TMDs) and reference torque wrenches (RTWs), respectively. The torque standard for RTWs has been disseminated in the range from $5 \mathrm{~N} \cdot \mathrm{m}$ to $5 \mathrm{kN} \cdot \mathrm{m}$ using two dead weight torque standard machines (DWTSMs) at NMIJ with rated capacities of $1 \mathrm{kN} \cdot \mathrm{m} \quad(1-\mathrm{kN} \cdot \mathrm{m}-\mathrm{DWTSM})$ and $20 \mathrm{kN} \cdot \mathrm{m} \quad(20-\mathrm{kN} \cdot \mathrm{m}-$ DWTSM).

To properly tighten screws, high-accuracy hand torque wrenches are used in precision mechanical equipment, medical devices, and other similar applications. Thus, there remains a strong demand to expand the lower end of the range of the torque standard for RTWs. In a previous study, we designed adaptations that allow torque transducers with a low nominal capacity to be mounted on the $10-\mathrm{N} \cdot \mathrm{m}-\mathrm{DWTSM}$ to expand the torque standard range for RTWs, and we demonstrated that RTWs could be calibrated using this modified $10-\mathrm{N} \cdot \mathrm{m}-$ DWTSM [2], [3]. The 10-N·m-DW'TSM has been compared with the $1 \mathrm{~N} \cdot \mathrm{m}$ and $1 \mathrm{kN} \cdot \mathrm{m}$ TSMs developed at the Physikalisch-Technische Bundesanstalt (PTB, Germany) by calibrating low-nominal capacity TMDs in the range of $0.1 \mathrm{~N} \cdot \mathrm{m}$ to $10 \mathrm{~N} \cdot \mathrm{m}$, and the torque realized by the $10-\mathrm{N} \cdot \mathrm{m}-\mathrm{DWTSM}$ at NMIJ was found to be equivalent to that realized by the two TSMs at PTB [4]. However, the RTW calibration capability of the $10-\mathrm{N} \cdot \mathrm{m}-\mathrm{DW}$ TSM has not been compared with those of other TSMs. To confirm the RTW calibration capability of the $10-\mathrm{N} \cdot \mathrm{m}-\mathrm{DWTSM}$, it was compared with the existing $1-\mathrm{kN} \cdot \mathrm{m}$ DWTSM at NMIJ by calibrating low-nominal capacity RTWs. 


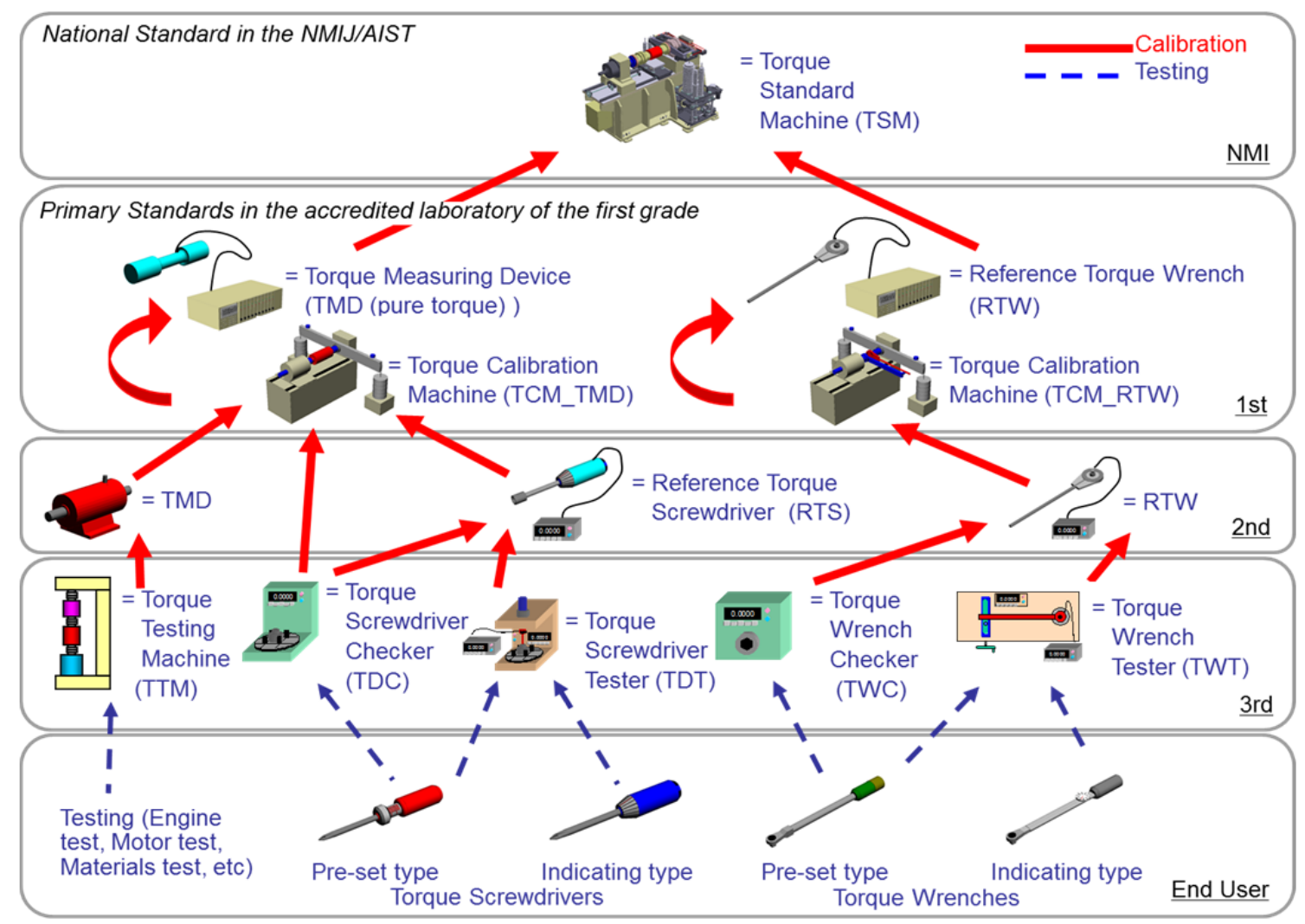

Figure 1. SI traceability system of torque in Japan [1].

The $1-\mathrm{kN} \cdot \mathrm{m}-\mathrm{DW} T S M$ was part of a CIPM Key Comparison (CCM.T-K1) [5] and was shown to yield results equivalent to those obtained using TSMs developed by other national metrology institutes. In addition, Ogushi et al. [6] conducted an inter-laboratory comparison of RTW calibrations in which the $1-\mathrm{kN} \cdot \mathrm{m}-\mathrm{DWTSM}$ at NMIJ and the $2 \mathrm{kN} \cdot \mathrm{m}$ Torque Calibration Machine at PTB were compared in the range of $10 \mathrm{~N} \cdot \mathrm{m}$ to 100 $\mathrm{N} \cdot \mathrm{m}$ under their respective procedures and demonstrated the equivalence of the RTW calibrations performed by NMIJ and PTB [6]. Moreover, the RTW calibration capability of the 20$\mathrm{kN} \cdot \mathrm{m}-\mathrm{DWTSM}$ at NMIJ was shown to be equivalent to that of the $1-\mathrm{kN} \cdot \mathrm{m}-\mathrm{DWTSM}$ at NMI [7]. In addition, an interlaboratory comparison of RTW calibration was conducted between NMIJ and PTB in the range from $200 \mathrm{~N} \cdot \mathrm{m}$ to 2 $\mathrm{kN} \cdot \mathrm{m}$, and agreement of the RTW calibration results of the two NMIs was confirmed for calibration steps above $600 \mathrm{~N} \cdot \mathrm{m}$ [8].

The calibration procedure of an RTW was based on the JMIF-016 (TTSG-W102) technical guideline established by NMIJ in cooperation with the Japanese industry [9]. The method of changing the mounting position of the transducer was outlined in the following manner:

5.5.3 The torque transducer should be calibrated in at least three directions $\left(0^{\circ}, 120^{\circ}\right.$, and $\left.240^{\circ}\right)$ by changing the torque transducer direction itself or the mechanical coupling adapter direction. Alternatively, if the torque transducer has the square drive, it would be useful, from the metrological point of view, to be calibrated in four directions $\left(0^{\circ}, 90^{\circ}, 180^{\circ}\right.$, and $\left.270^{\circ}\right)[9]$.

Thus, there are two methods of changing the RTW mounting position: one involving "changing the sensing body direction together with the lever" and the other involving "changing the detachable square drive direction without changing the sensing body direction." Except in special circumstances, the former has been recommended by NMIJ because changing the rotational mounting position at only mechanical parts including the square drive is not recognized as truly changing the direction of the sensing element. This method requires a sufficient amount of space around the TSM. The $1-\mathrm{kN} \cdot \mathrm{m}-$ and $20-\mathrm{kN} \cdot \mathrm{m}$-DWTSMs have sufficient space to change the torque transducer direction itself in the $120^{\circ}$ and $240^{\circ}$ directions. However, it is not possible to mount the torque transducer on the $10-\mathrm{N} \cdot \mathrm{m}-\mathrm{DW}$ TSM in the $120^{\circ}$ or $240^{\circ}$ direction because there is not sufficient space under the measurement axis in this compactly designed machine. The RTW must be mounted in the $0^{\circ}, 90^{\circ}$, and $270^{\circ}$ directions when it is calibrated by the 10 $\mathrm{N} \cdot \mathrm{m}$-DWTSM. Thus, it was necessary to investigate whether the difference in the combination of lever angles affected the calibration results before the $10-\mathrm{N} \cdot \mathrm{m}-$ and $1-\mathrm{kN} \cdot \mathrm{m}-\mathrm{DW}$ TSMs were compared.

In this study, the effect of the difference between the two abovementioned sets of RTW mounting positions on the calibration results was first investigated. Despite the difference between the mounting positions for the $10-\mathrm{N} \cdot \mathrm{m}$ - and $1-\mathrm{kN} \cdot \mathrm{m}-$ DWTSMs, an intra-laboratory comparison between the 10$\mathrm{N} \cdot \mathrm{m}-$ and $1-\mathrm{kN} \cdot \mathrm{m}-\mathrm{DWTSM}$ was then conducted regarding RTW calibrations in the torque range of $5 \mathrm{~N} \cdot \mathrm{m}$ to $10 \mathrm{~N} \cdot \mathrm{m}$. Finally, the capability of the 10-N.m-DWTSM in the calibration of low-nominal capacity RTWs at NMIJ was then confirmed.

\section{EXPERIMENTAL CONDITIONS}

\subsection{Difference of the combination of lever angles when changing the RTW mounting position}

First, the effect of the difference between the mounting positions of RTWs on the calibration results was investigated. Because there is not sufficient space around the $10-\mathrm{N} \cdot \mathrm{m}$ - 
DWTSM to change the RTW mounting position at intervals of $120^{\circ}$, this experiment was conducted using the $1-\mathrm{kN} \cdot \mathrm{m}-$ and $20-\mathrm{kN} \cdot \mathrm{m}-\mathrm{DW} T S M$ s. Figures 2 and 3 show schematics of how the mounting position was changed by changing the sensing body direction to the $0^{\circ}, 120^{\circ}$, and $240^{\circ}$ directions (case 1 ) and the $0^{\circ}, 90^{\circ}$, and $270^{\circ}$ directions (case 2), respectively. In these cases, the lever direction was also changed to align with the sensing body direction. Case 1 was used for the daily calibrations of the $1-\mathrm{kN} \cdot \mathrm{m}-$ and $20-\mathrm{kN} \cdot \mathrm{m}-\mathrm{DWTSM}$ at NMIJ, whereas case 2 was used for the $10-\mathrm{N} \cdot \mathrm{m}$-DWTSM.

To estimate the effect of these different sets of RTW mounting positions on the calibration results, three RTWs were calibrated using these different cases. Table 1 gives the experimental conditions. The mounting positions of the RTWs were changed to the sets of directions in cases 1 and 2. In this experiment, torque transducers with rated capacities of $50 \mathrm{~N} \cdot \mathrm{m}$ (TS50) and $1 \mathrm{kN} \cdot \mathrm{m}$ (TTS/1000Nm) were calibrated using the 1-kN.m-DWTSM, and a torque transducer with a rated capacity of $5 \mathrm{kN} \cdot \mathrm{m}$ (TS5000R) was calibrated using the 20$\mathrm{kN} \cdot \mathrm{m}$-DWTSM. The direction of the torque transducers was changed as shown in Figures 2 and 3. The characteristics of these transducers have already been evaluated and were found to be similar in the clockwise $(\mathrm{CW})$ and counterclockwise (CCW) directions. Thus, they were calibrated in only one direction in this study. Table 2 gives the calibration ranges and calibration and measurement capabilities (CMCs) of the torque standard machines (TSMs) at NMIJ [10]-[12]. Figure 4 shows a

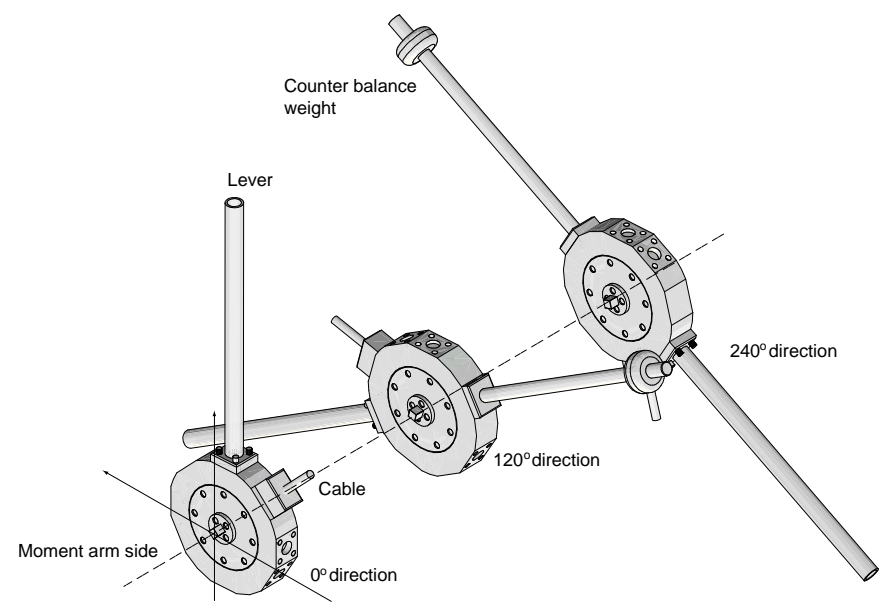

Figure 2. Schematic showing how the mounting position was changed by changing the lever direction in case 1.

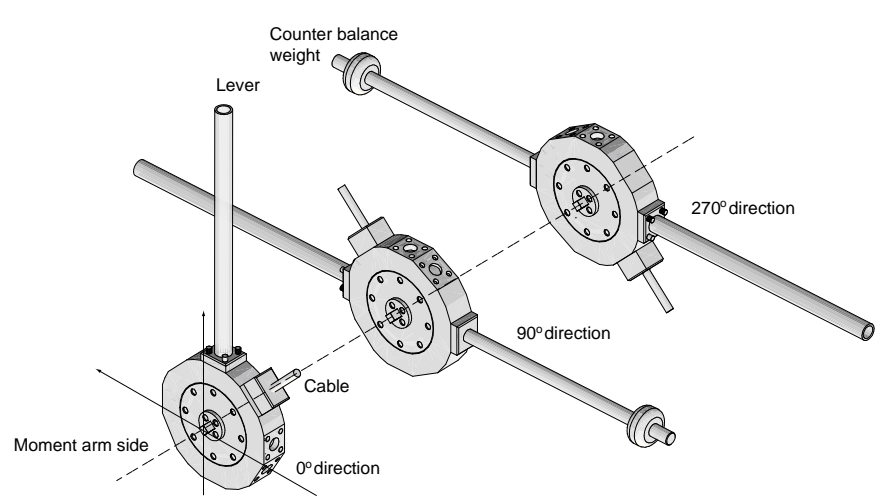

Figure 3. Schematic showing how the mounting position was changed by changing the lever direction in case 2.

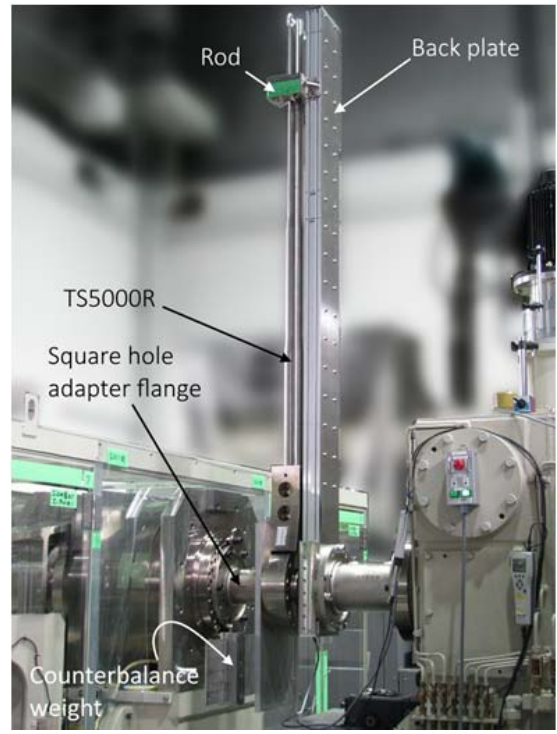

Figure 4. Photograph of the TS5000R mounted on the 20-kN.m-DWTSM.

photograph of the TS5000R mounted on the $20-\mathrm{kN} \cdot \mathrm{m}$ DWTSM. The back plate, rod, square hole adapter flange, and counterbalance weight were used to mount the RTW on the 20$\mathrm{kN} \cdot \mathrm{m}-\mathrm{DWTSM}$. Similarly, Figure 5 shows a photograph of the TS50 mounted on the $1-\mathrm{kN} \cdot \mathrm{m}-\mathrm{DWTSM}$. The RTW is clamped by the square hole adapter. Then, the RTW mounting position was changed by rotating the RTW and the square hole adapter in a body. Thus, the square drive was kept attached to the square hole adapter all the time during the calibrations. The details of the procedure have been described in [1]. The installation procedure of the counterbalance weights is determined to each RTW based on its weight and shape. Figure 6 shows a schematic of the loading cycle conducted in accordance with the JMIF-016 (TTSG-W102) guideline [9]. Eight torque steps $(10 \%, 20 \%, 30 \%, 40 \%, 50 \%, 60 \%, 80 \%$, and $100 \%$ of the maximum torque of each torque transducer) were applied. The lever length $L$ was changed in the final mounting position. $l_{\max }$ and $l_{\min }$ are the average and minimum lever lengths, respectively. The DMP40S2 (HBM GmbH, Germany) was used as the indicator/amplifier. A $0.1 \mathrm{~Hz}$ Bessel filter was employed as a low-pass filter.

\subsection{Intra-laboratory comparison}

An intra-laboratory comparison of the $10-\mathrm{N} \cdot \mathrm{m}-$ and 1 $\mathrm{kN} \cdot \mathrm{m}$-DWTSMs was conducted to confirm the capability of

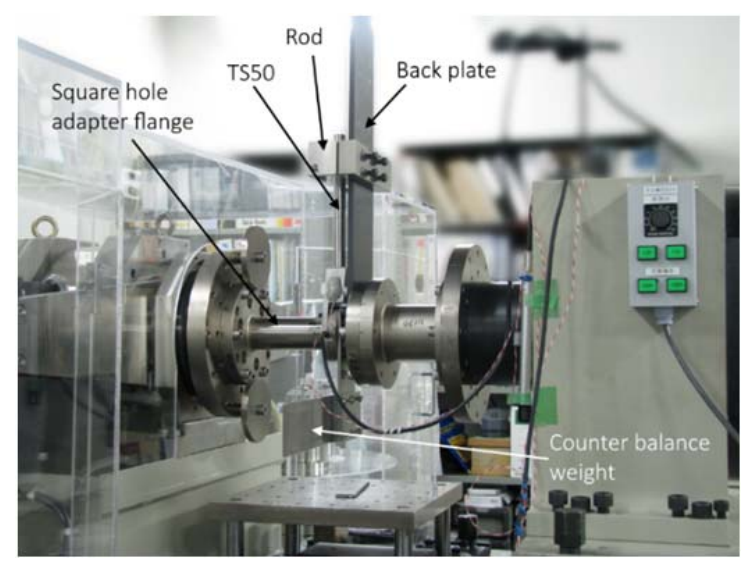

Figure 5. Photograph of the TS50 mounted on the 1-kN.m-DWTSM. 
Table 1. Experimental conditions.

\begin{tabular}{|c|c|c|c|c|c|}
\hline $\begin{array}{c}\text { Torque } \\
\text { transducers }\end{array}$ & $\begin{array}{c}\text { Capacity / } \\
\mathrm{N} \cdot \mathrm{m}\end{array}$ & TSM & Direction & $\begin{array}{c}\text { Lever length / mm } \\
I_{\max } / I_{\min }\end{array}$ & $\begin{array}{l}\text { Changing the mounting } \\
\text { position }\end{array}$ \\
\hline TS50 & 50 & 1-kN·m-DWTSM & CCW & $250 / 200$ & Case $\left.1^{*}\right) /$ Case $2^{* *}$ \\
\hline TTS $/ 1000 \mathrm{Nm}$ & 1000 & 1-kN·m-DWTSM & $\mathrm{CW}$ & $1000 / 700$ & Case $1^{*} /$ Case $2^{* *}$ \\
\hline TS5000R & 5000 & 20-kN·m-DWTSM & $\mathrm{CCW}$ & $1750 / 1400$ & Case $1^{*)} /$ Case $2^{* *}$ \\
\hline
\end{tabular}

*) Case $1: 0^{\circ}, 120^{\circ}, 240^{\circ}$

Table 2. Calibration ranges and CMCs of TSMs at NMIJ.

\begin{tabular}{ccc}
\hline TSM & TMD & RTW \\
& $\begin{array}{c}\text { Calibration range } \\
(\text { CMC })\end{array}$ & $\begin{array}{c}\text { Calibration range } \\
(C M C)\end{array}$ \\
\hline $10-\mathrm{N} \cdot \mathrm{m}-$ DWTSM & $0.1 \mathrm{~N} \cdot \mathrm{m}-10 \mathrm{~N} \cdot \mathrm{m}$ & $0.1 \mathrm{~N} \cdot \mathrm{m}-10 \mathrm{~N} \cdot \mathrm{m}$ \\
& $\left(1.0 \times 10^{-4}\right)$ & $\left(3.0 \times 10^{-4}\right)$ \\
$1-\mathrm{kN} \cdot \mathrm{m}-$ DWTSM & $2 \mathrm{~N} \cdot \mathrm{m}-20 \mathrm{~N} \cdot \mathrm{m}$ & $2 \mathrm{~N} \cdot \mathrm{m}-20 \mathrm{~N} \cdot \mathrm{m}$ \\
& $\left(1.0 \times 10^{-4}\right)$ & $\left(3.0 \times 10^{-4}\right)$ \\
& $5 \mathrm{~N} \cdot \mathrm{m}-1 \mathrm{kN} \cdot \mathrm{m}$ & $5 \mathrm{~N} \cdot \mathrm{m}-1 \mathrm{kN} \cdot \mathrm{m}$ \\
$20-\mathrm{kN} \cdot \mathrm{m}-$ DWTSM & $\left(5.0 \times 10^{-5}\right)$ & $\left(7.0 \times 10^{-5}\right)$ \\
& $200 \mathrm{~N} \cdot \mathrm{m}-20 \mathrm{kN} \cdot \mathrm{m}$ & $200 \mathrm{~N} \cdot \mathrm{m}-5 \mathrm{kN} \cdot \mathrm{m}$ \\
& $\left(7.0 \times 10^{-5}\right)$ & $\left(1.0 \times 10^{-4}\right)$ \\
\hline
\end{tabular}
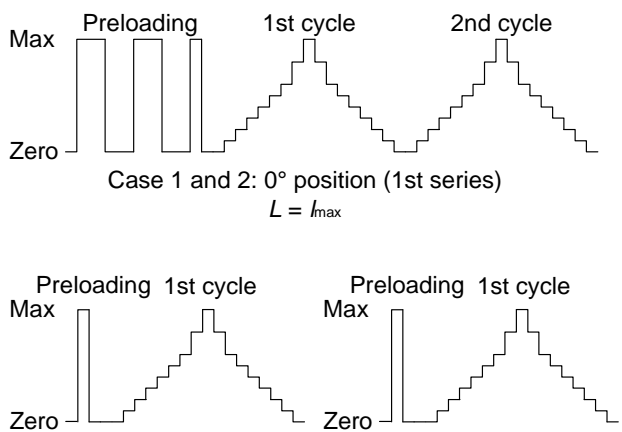

Case 1: $120^{\circ}$ and $240^{\circ}$ position Case $1: 240^{\circ}$ position Case 2: $90^{\circ}$ and $270^{\circ}$ position Case 2: $270^{\circ}$ position

$$
\text { (2nd and 3rd series) (4th series) }
$$$$
L=I_{\max }
$$$$
L=I_{\min }
$$

Figure 6. Schematic of the loading cycle conducted in accordance with the JMIF-016 guideline.

the $10-\mathrm{N} \cdot \mathrm{m}-\mathrm{DWTSM}$ in the calibration of low-nominal capacity RTWs at NMIJ.

\subsubsection{Reference torque wrenches}

Figure 7 shows the high-accuracy torque transducers DmTS/10Nm (GTM GmbH, Germany) and TP-5N-1109 (Showa Measuring Instruments Co., Ltd., Japan), which are components of the traveling standards with rated capacities of $10 \mathrm{~N} \cdot \mathrm{m}$ and $5 \mathrm{~N} \cdot \mathrm{m}$. They were connected to an indicator/ amplifier (DMP40S2) with specific cables to form RTWs. Table 3 gives the specifications of the two types of torque transducers and the experimental conditions. The square drive of each torque transducer is $6.3 \mathrm{~mm}$. $l_{\max }$ and $l_{\min }$ of each torque transducer are $200 \mathrm{~mm}$ and $140 \mathrm{~mm}$, respectively. A $0.1 \mathrm{~Hz}$ Bessel filter was employed as a low-pass filter. Various characteristics of the RTW, such as its temperature and humidity characteristics, and the short-term drift have already

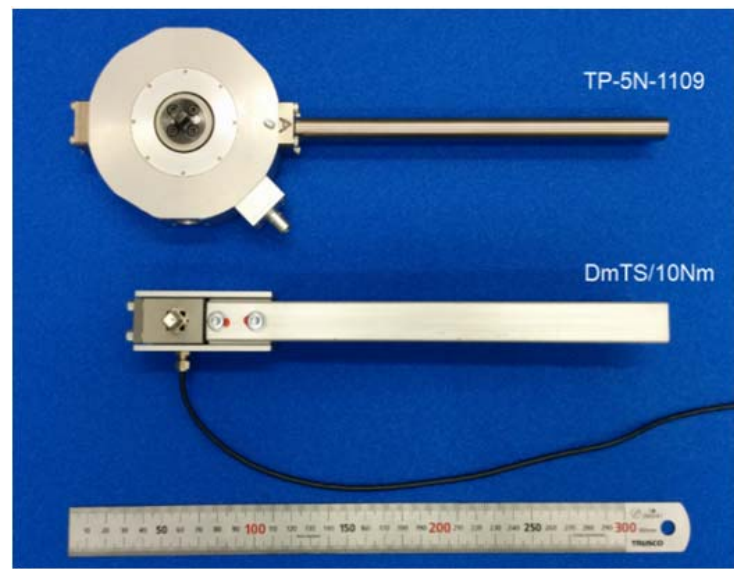

Figure 7. Photograph of TP-5N-1109 and DmTS/10Nm.

been revealed. Although the $10-\mathrm{N} \cdot \mathrm{m}-$ and $1-\mathrm{kN} \cdot \mathrm{m}-\mathrm{DWTSM}$ were set up in different buildings, the environmental conditions, such as the temperature and humidity, were nearly equivalent in each room. Thus, the temperature and humidity dependence of the RTWs was not considered. The short-term drift was considered by taking measurements in the following order: the $10-\mathrm{N} \cdot \mathrm{m}-\mathrm{DWTSM}$ (pre-calibration), the $1-\mathrm{kN} \cdot \mathrm{m}-$ DWTSM, and the $10-\mathrm{N} \cdot \mathrm{m}-\mathrm{DWTSM}$ (post-calibration).

\subsubsection{Torque standard machines}

Figures 8 and 9 show schematics of the $10-\mathrm{N} \cdot \mathrm{m}-$ and 1 $\mathrm{kN} \cdot \mathrm{m}$-DWTSMs, respectively, and Table 4 gives the characteristics of the two TSMs. The lever deadweight system was adopted in each TSM. The relative expanded uncertainty of torque realized by the $10-\mathrm{N} \cdot \mathrm{m}$-DWTSM was $6.6 \times 10^{-5}$ in the $0.1 \mathrm{~N} \cdot \mathrm{m}$ to $10 \mathrm{~N} \cdot \mathrm{m}$ torque range [12]. To realize a low-nominal capacity torque standard, a binary mass stack exchange system was adopted as the weight loading system of the $10-\mathrm{N} \cdot \mathrm{m}-$

Table 3. Specifications of low-nominal capacity torque transducers and experimental conditions.

\begin{tabular}{cccccc}
\hline Type & Rated capacity / $\mathbf{N} \cdot \mathbf{m}$ & Square drive $/ \mathbf{m m}$ & $\boldsymbol{I}_{\max } / \mathbf{m m}$ & $\boldsymbol{I}_{\min } / \mathbf{m m}$ & Changing the mounting position \\
\hline DmTS/10Nm & 10 & 6.3 & 200 & 140 & $\begin{array}{c}\text { Square drive direction } \\
\text { TP-5N-1109 }\end{array}$ \\
\hline
\end{tabular}




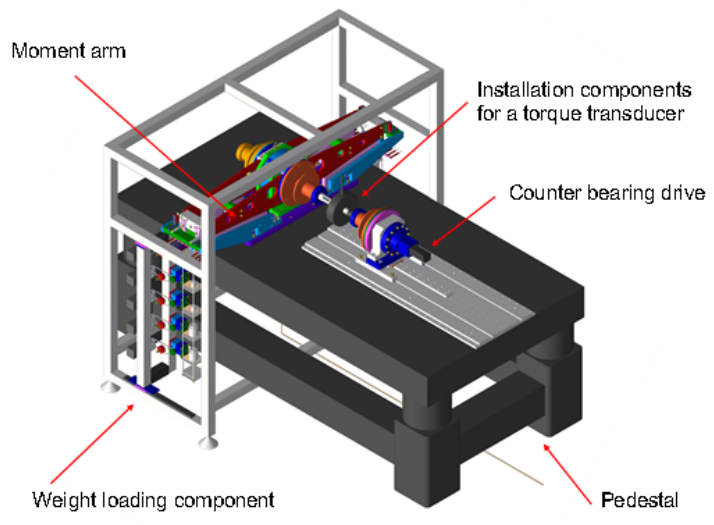

Figure 8 . Schematic of the 10-N.m-DWTSM.

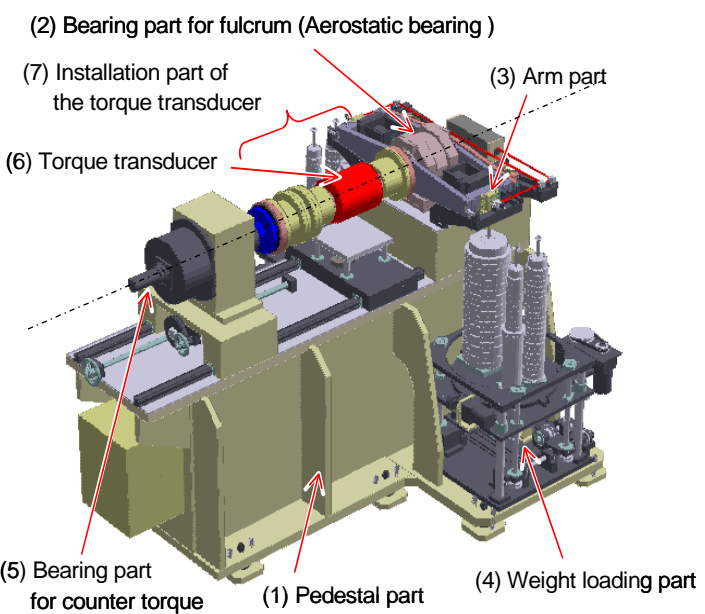

Figure 9. Schematic of the 1-kN.m-DWTSM.

DWTSM. In accordance with OIML R111, weights were prepared in a series from $10 \mathrm{~g}$ to $1 \mathrm{~kg}$. The aerostatic bearing was adopted as a fulcrum supporting the moment arm to minimize rotational friction. The moment arms are made of low-thermal expansion alloy (Super INVAR). Two types of square hole adapters with different apical parts were prepared. One is an insertion-type adapter, which only allows the insertion of the square drive of a torque transducer, and the other is a tightening-type adapter, which is tightened with screws. Figure 10 shows a photograph of the square hole adapters and a flange of the $10-\mathrm{N} \cdot \mathrm{m}-\mathrm{DWTSM}$. Figure 11 shows the rod component of the 10-N.m-DWTSM, which acts as the counter loading point. An aerostatic shaft with a collar was adopted to reduce any parasitic forces [3].

The relative expanded uncertainty of the torque realized by the $1-\mathrm{kN} \cdot \mathrm{m}-\mathrm{DWTSM}$ was $4.9 \times 10^{-5}$ in the $5 \mathrm{~N} \cdot \mathrm{m}$ to $1 \mathrm{kN} \cdot \mathrm{m}$

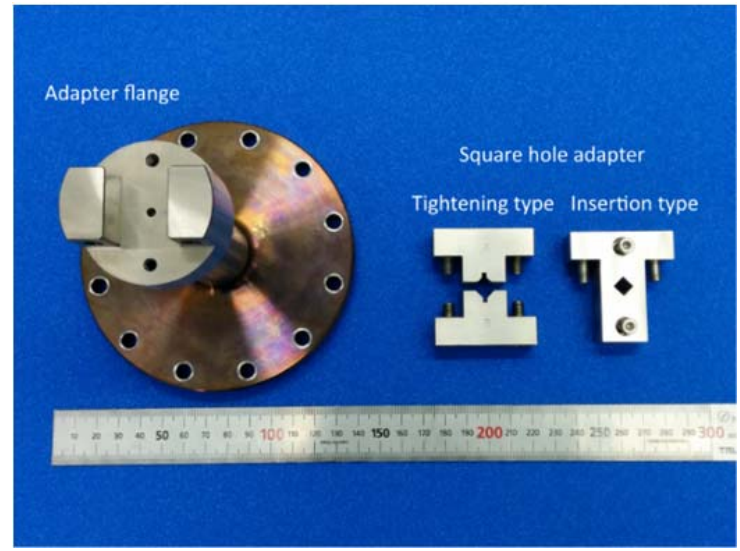

Figure 10. Photograph of square hole adapters and a flange of the $10-\mathrm{N} \cdot \mathrm{m}$ DWTSM.

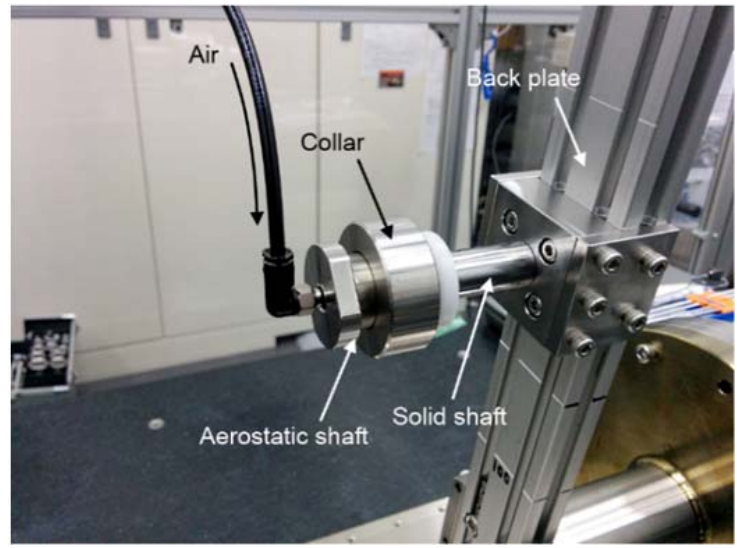

Figure 11. Photograph of the rod component of the 10-N.m-DWTSM, which acts as the counter loading point.

torque range [10]. Linkage weights were adopted as the weights for this DWTSM. The moment arms of the $1-\mathrm{kN} \cdot \mathrm{m}-\mathrm{DWWTSM}$ are made of austenitic stainless steel. To correct the moment arm length, the temperature of the moment arms was monitored by platinum thermometers. The square hole adapter of the $1-\mathrm{kN} \cdot \mathrm{m}$-DWTSM is the tightening-type adapter, and a solid shaft was adopted as the counter loading point.

\subsubsection{Calibration procedure}

The calibration procedure and conditions were based on the JMIF-016 (TTSG-W102) guideline [9]. The mounting position of the DmTS/10Nm was changed by changing the direction of the detachable square drive, as indicated in Table 3 , because the counterbalance weights could not be attached to it. Note that, without these weights, the moment arm of any DWTSM could not be balanced, leading to disablement of the DWTSM for the

Table 4. Characteristics of the $10-\mathrm{N} \cdot \mathrm{m}$ - and $1-\mathrm{kN} \cdot \mathrm{m}-\mathrm{DWTSMs}$.

\begin{tabular}{lll}
\hline & 10-N·m-DWTSM & 1-kN·m-DWTSM \\
\hline Calibration range & $0.1 \mathrm{~N} \cdot \mathrm{m}-10 \mathrm{~N} \cdot \mathrm{m}$ & $5 \mathrm{~N} \cdot \mathrm{m}-1 \mathrm{kN} \cdot \mathrm{m}$ \\
$W_{\text {tsm }}(k=2)$ & $6.6 \times 10^{-5}$ & $4.9 \times 10^{-5}$ \\
Weights & Weights according to OIML R111 & Linkage weights \\
Fulcrum & & Aerostatic bearing \\
Material of moment arm & Super Invar & Austenitic stainless steel \\
Square hole adapter & Tightening type or insertion type & Tightening type \\
Rod & Aerostatic shaft with a collar & Solid shaft \\
\hline
\end{tabular}


RTW calibrations. In contrast, because the counterbalance weights could be mounted on the TP- $5 \mathrm{~N}-1109$, its mounting position was changed by changing the sensing body direction, as described in Section 2.1. Figures 12, 13, and 14 show
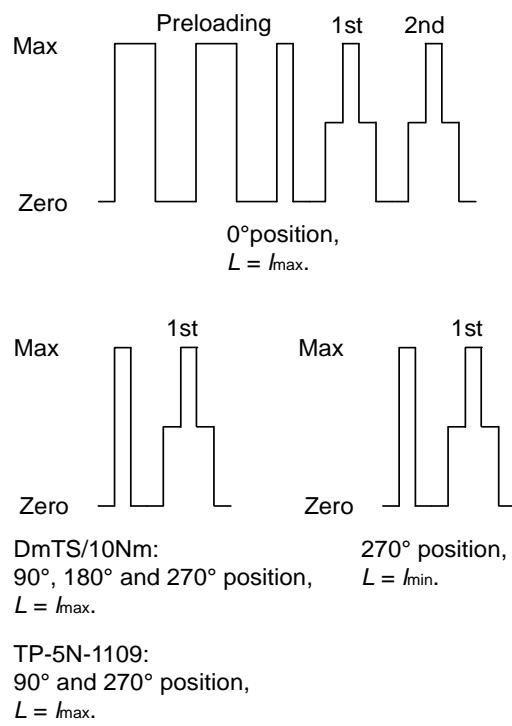

Figure 12. Schematic of loading timetable for intra-laboratory comparison between the $10-\mathrm{N} \cdot \mathrm{m}$ - and $1-\mathrm{kN} \cdot \mathrm{m}-\mathrm{DWTSMs}$.

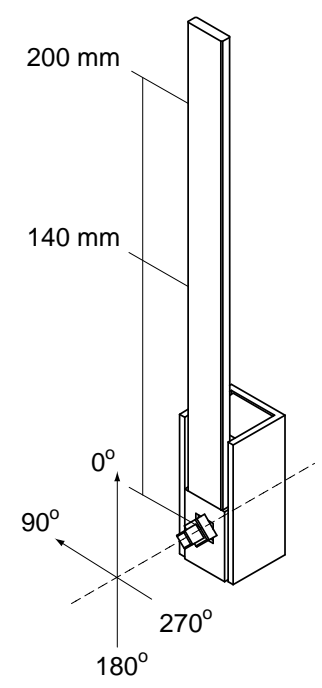

Figure 13. Schematic of how the mounting position was changed by changing the square drive direction for the DmTS/10Nm.

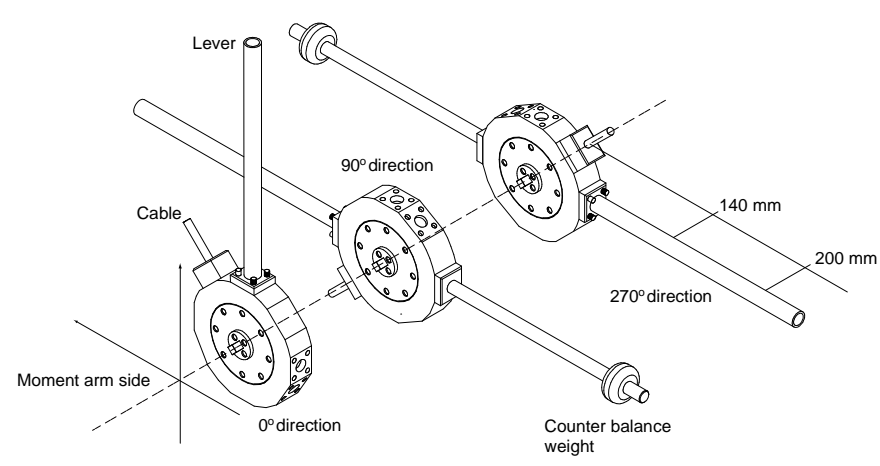

Figure 14. Schematic of how the mounting position was changed by changing the lever direction for the TP-5N-1109. schematics of the loading timetable and the rotational mounting positions of the DmTS/10Nm and TP-5N-1109, respectively.

The mounting position of the DmTS $/ 10 \mathrm{Nm}$ was set to four directions $\left(0^{\circ}, 90^{\circ}, 180^{\circ}\right.$, and $\left.270^{\circ}\right)$ by changing the mounting position of its square drive. This allowed the mounting position of the torque transducer to be maintained in the $0^{\circ}$ direction. Two torque calibration steps $(50 \%$ and $100 \%$ of the maximum torque) were applied. The lever length was changed from $l_{\max }=$ $200 \mathrm{~mm}$ to $l_{\min }=140 \mathrm{~mm}$ by moving the $\operatorname{rod}$ as the counter loading point in the final mounting position. The mounting position of the TP-5N-1109 was set to three directions $\left(0^{\circ}, 90^{\circ}\right.$, and $\left.270^{\circ}\right)$. The counterbalance weights were installed in the TP$5 \mathrm{~N}-1109$ when it was mounted in the $90^{\circ}$ and $270^{\circ}$ directions, as shown in Figure 14. One torque step $(100 \%$ of the maximum torque) was applied. As with the DmTS $/ 10 \mathrm{Nm}$, the lever length was changed from $l_{\max }=200 \mathrm{~mm}$ to $l_{\min }=140 \mathrm{~mm}$ in the final mounting position.

Figures 15 and 16 show photographs of the DmTS/10Nm and TP-5N-1109, respectively, mounted on a TSM. An initial torque of $1 \%$ or $2 \%$ of the maximum torque of each RTW was applied by placing a small weight on the end of the moment arm of each TSM. The RTWs were calibrated separately in the $\mathrm{CW}$ and $\mathrm{CCW}$ directions.

\subsubsection{Environmental conditions and measurement dates}

Table 5 gives the environmental conditions that must be satisfied when conducting a calibration in NMIJ. The present comparison was conducted at a temperature of $23{ }^{\circ} \mathrm{C} \pm 1{ }^{\circ} \mathrm{C}$. The environmental conditions were nearly equivalent in the laboratories of the $10-\mathrm{N} \cdot \mathrm{m}-$ and $1-\mathrm{kN} \cdot \mathrm{m}-\mathrm{DWTSM}$. Table 6 gives the measurement dates of the intra-laboratory comparison. This comparison was conducted in the spring to achieve a stable room temperature of $23{ }^{\circ} \mathrm{C}$.

\section{RESULTS AND DISCUSSION}

\subsection{Difference of the calibration results between case 1 and case 2}

The arithmetic averages $\overline{S_{n, i}}$ of the measurement results at the three mounting positions $\left(0^{\circ}, 120^{\circ}\right.$, and $240^{\circ}$ for case 1 and $0^{\circ}, 90^{\circ}$, and $240^{\circ}$ for case 2 ) were obtained for each torque step, where $n=$ case1, case 2 indicates the set of mounting positions and $i$ is the calibration step. The uncertainties $W_{n, i}$ were evaluated in accordance with JCG209S11 [13], which is a guideline for evaluating the uncertainty of calibrations of TMDs and RTWs that was issued by the International Accreditation Japan at the National Institute of Testing and Evaluation

Table 5. Environmental conditions for calibrations in NMIJ.

\begin{tabular}{lccc}
\hline $\begin{array}{l}\text { Environmental } \\
\text { conditions }\end{array}$ & Minimum & Maximum & $\begin{array}{l}\text { Acceptable } \\
\text { variations }\end{array}$ \\
\hline $\begin{array}{l}\text { Temperature } \\
\text { Relative humidity }\end{array}$ & $18^{\circ} \mathrm{C}$ & $28^{\circ} \mathrm{C}$ & $<1 \mathrm{~K}$ \\
$\begin{array}{l}\text { Atmospheric } \\
\text { pressure }\end{array}$ & $20 \%$ & $70 \%$ & $<10 \%$ \\
\hline
\end{tabular}

Table 6. Measurement dates of the intra-laboratory comparison.

\begin{tabular}{ll}
\hline Date & TSM \\
\hline May 29-30, 2014 & 10-N.m-DWTSM (Pre-calibration) \\
June 3, 2014 & 1-kN.m-DWTSM \\
June 4-5, 2014 & 10-N.m-DWTSM (Post-calibration) \\
\hline
\end{tabular}




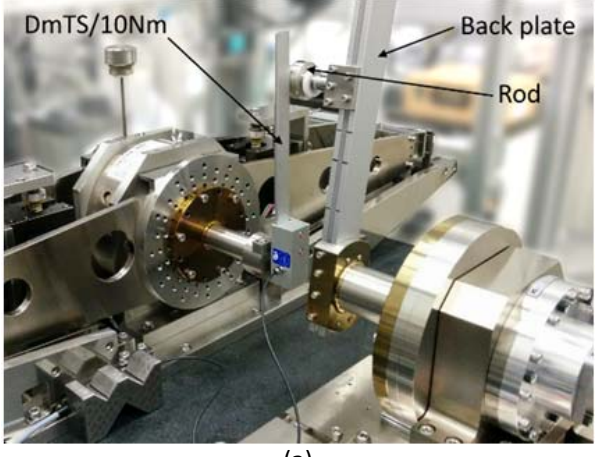

(a)

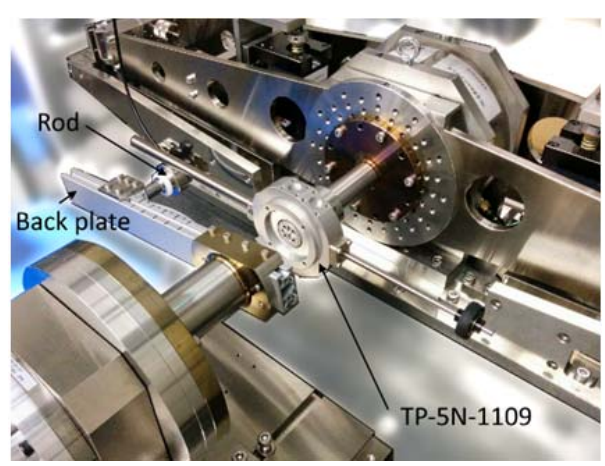

(b)

Figure 15. Photograph of torque transducers mounted on the 10-N.m-DWTSM. (a) DmTS/10Nm ( $0^{\circ}$ mounting direction). (b) TP-5N-1109 (270 mounting direction).

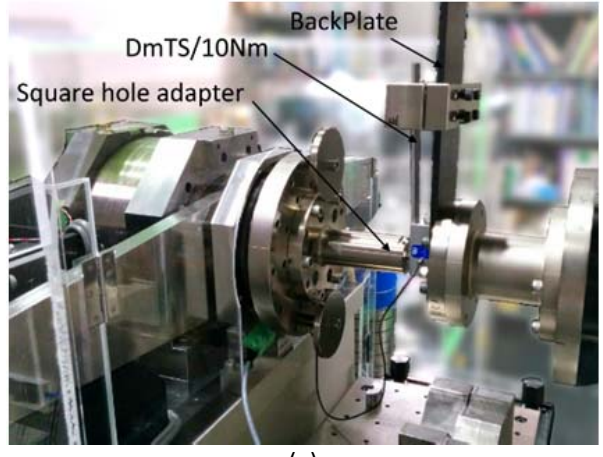

(a)

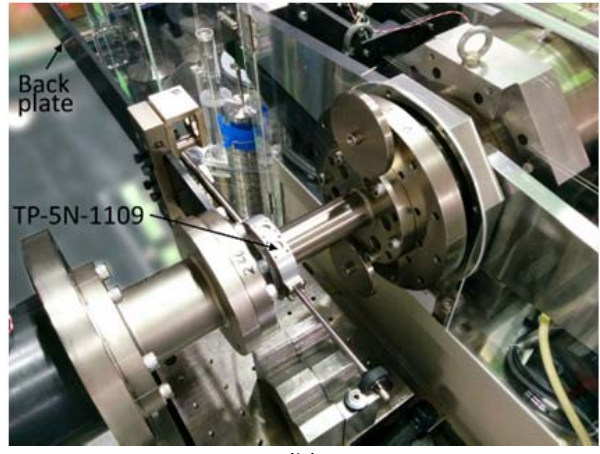

(b)

Figure 16. Photograph of torque transducers mounted on the $1-k N \cdot m-D W T S M . ~(a) ~ D m T S / 10 N m ~\left(0^{\circ}\right.$ mounting direction). (b) TP-5N-1109 (270 ${ }^{\circ}$ mounting direction).

(IAJapan/NITE), an accreditation body for calibration and testing laboratories in Japan. The relative deviation $R D_{i}$ is expressed as

$R D_{i}=\frac{\overline{S_{n, i}}-\overline{S_{\text {case } 1, i}}}{\mid \overline{S_{\text {ave }, i} \mid}}$,

where $\overline{S_{\text {ave, }}}$ is given by

$\overline{S_{\mathrm{ave}, i}}=\frac{\overline{S_{\mathrm{case} 1, i}}+\overline{S_{\mathrm{case} 2, i}}}{2}$.

Tables 7, 8, and 9 give the calibration results for the TS50, TTS $/ 1000 \mathrm{Nm}$, and TS5000R, respectively. Absolute values of the measurement results obtained in case 2 were larger than those in case 1 under most of the considered calibration conditions, and the magnitudes of the uncertainties $W_{n, i}$ in case 1 were slightly larger than or almost equal to those in case 2 . We presume that the reason for this is due to the larger mounting position interval in case 1 than that in case 2, resulting in slightly larger reproducibility in different mounting positions.

The En number is expressed as

$$
E n_{i}=\frac{R D_{i}}{\sqrt{W_{\text {case } 1, i}^{2}+W_{\text {case }, i}^{2}}} .
$$

En numbers were less than one at all torque steps as shown Tables 7, 8 and 9. Thus, the agreement of the RTW calibration results of the two procedures was confirmed. In principle, the calibration procedure for an RTW is based on case 1 . However, it was demonstrated that the calibration procedure based on case 2 can yield results consistent with those obtained using the procedure based on case 1 .

\subsection{Intra-laboratory comparison}

The comparison results for the DmTS/10Nm with the torque changed at intervals of $+5 \mathrm{~N} \cdot \mathrm{m},+10 \mathrm{~N} \cdot \mathrm{m}$, and $-5 \mathrm{~N} \cdot \mathrm{m}$ are shown in Figures 17, 18, and 19, respectively. The arithmetic averages $\overline{S_{h, i}}$ of the measurement results at mounting positions of $0^{\circ}, 90^{\circ}, 180^{\circ}$, and $270^{\circ}$ were obtained for each torque step, where $h=$ A_pre, A_post, and B indicates the pre- and post-calibration results obtained using the 10$\mathrm{N} \cdot \mathrm{m}$-DWTSM and the results obtained using the $1-\mathrm{kN} \cdot \mathrm{m}$ DWTSM, respectively. $R D$ is expressed as

$R D_{i}=\frac{\overline{S_{\mathrm{B}, i}}-\overline{S_{\mathrm{A} \_ \text {ave }, i}}}{\mid \overline{S_{\mathrm{A} \_ \text {ave }, i} \mid}}$,

where $\overline{S_{\text {A_ave, }}}$ is given by

$\overline{S_{\mathrm{A} \_ \text {ave }, i}}=\frac{\overline{S_{\mathrm{A} \_ \text {pre }, i}}+\overline{S_{\mathrm{A} \_ \text {post }, i}}}{2}$.

In Figures 17, 18, and 19, zero on the vertical axis is the average of the pre- and post-calibration results obtained using the $10-\mathrm{N} \cdot \mathrm{m}-\mathrm{DWTSM}$. The bars represent the relative expanded uncertainty $W_{b}$ of the measurement results, which is given by

$W_{h, i}=k \cdot w_{h, i}=k \sqrt{W_{\mathrm{tsm} \_\underline{h}}{ }^{2}+w_{\mathrm{tra} \_, h, i}^{2}}$,

where $k$ is the coverage factor, $w_{\mathrm{tsm}_{-} b}$ is the relative combined standard uncertainty of torque realized by the TSM, and $w_{\text {tra_bs,i }}$ 
Table 7. Calibration results for the TS50.

\begin{tabular}{|c|c|c|c|c|c|c|}
\hline \multirow{2}{*}{ Torque / $\mathrm{N} \cdot \mathrm{m}$} & \multicolumn{2}{|l|}{ Case 1} & \multicolumn{2}{|l|}{ Case 2} & \multirow{2}{*}{$R D$} & \multirow{2}{*}{ En } \\
\hline & $\overline{S_{\text {case } 1, i}} /(\mathrm{mV} / \mathrm{v})$ & $w / \%$ & $\overline{S_{\text {case } 2, i}} /(\mathrm{mV} / \mathrm{V})$ & $w / \%$ & & \\
\hline-5 & -0.171168 & 0.15 & -0.171176 & 0.13 & -0.000046 & -0.02 \\
\hline-10 & -0.342361 & 0.11 & -0.342371 & 0.10 & -0.000029 & -0.02 \\
\hline-15 & -0.513570 & 0.082 & -0.513593 & 0.071 & -0.000046 & -0.04 \\
\hline-20 & -0.684799 & 0.063 & -0.684839 & 0.054 & -0.000058 & -0.07 \\
\hline-25 & -0.856056 & 0.051 & -0.856118 & 0.043 & -0.000073 & -0.11 \\
\hline-30 & -1.027342 & 0.044 & -1.027420 & 0.037 & -0.000077 & -0.13 \\
\hline-40 & -1.369798 & 0.037 & -1.369926 & 0.030 & -0.000094 & -0.20 \\
\hline-50 & -1.712257 & 0.028 & -1.712424 & 0.020 & -0.000098 & -0.28 \\
\hline
\end{tabular}

Table 8. Calibration results for the TTS/1000Nm.

\begin{tabular}{|c|c|c|c|c|c|c|c|}
\hline \multirow{2}{*}{ Torque / N-m } & \multicolumn{2}{|l|}{ Case 1} & \multicolumn{3}{|c|}{ Case 2} & \multirow{2}{*}{$R D$} & \multirow{2}{*}{ En } \\
\hline & $\overline{S_{\text {case } 1, i}} /(\mathrm{mv} / \mathrm{v})$ & $w / \%$ & $\overline{S_{\text {case } 2 i}}$ & $/(\mathrm{mV} / \mathrm{V})$ & $w / \%$ & & \\
\hline 100 & 0.158576 & 0.27 & 0.1 & 58594 & 0.27 & 0.000115 & 0.03 \\
\hline 200 & 0.316898 & 0.17 & 0.3 & 16925 & 0.17 & 0.000083 & 0.03 \\
\hline 300 & 0.475182 & 0.11 & 0.4 & 75205 & 0.10 & 0.000049 & 0.03 \\
\hline 400 & 0.633468 & 0.067 & 0.6 & 33493 & 0.065 & 0.000039 & 0.04 \\
\hline 500 & 0.791752 & 0.048 & 0.7 & 91782 & 0.046 & 0.000038 & 0.06 \\
\hline 600 & 0.950021 & 0.042 & 0.9 & 50056 & 0.041 & 0.000037 & 0.06 \\
\hline 800 & 1.266550 & 0.042 & & 66588 & 0.043 & 0.000030 & 0.05 \\
\hline 1000 & 1.583038 & 0.018 & 1.5 & 83076 & 0.019 & 0.000024 & 0.09 \\
\hline
\end{tabular}

Table 9. Calibration results for the TS5000R.

\begin{tabular}{|c|c|c|c|c|c|c|}
\hline \multirow[b]{2}{*}{ Torque / N·m } & \multicolumn{2}{|l|}{ Case 1} & \multicolumn{2}{|l|}{ Case 2} & \multirow[b]{2}{*}{$R D$} & \multirow[b]{2}{*}{ En } \\
\hline & $\overline{S_{\text {case } 1, i}} /(\mathrm{mv} / \mathrm{v})$ & $w / \%$ & $\overline{S_{\text {case } 2 i}} /(\mathrm{mv} / \mathrm{v})$ & $w / \%$ & & \\
\hline-500 & -0.139539 & 0.011 & -0.139539 & 0.012 & 0.000004 & 0.02 \\
\hline-1000 & -0.279084 & 0.010 & -0.279088 & 0.010 & -0.000014 & -0.10 \\
\hline-1500 & -0.418627 & 0.010 & -0.418637 & 0.010 & -0.000024 & -0.17 \\
\hline-2000 & -0.558171 & 0.010 & -0.558186 & 0.010 & -0.000027 & -0.19 \\
\hline-2500 & -0.697712 & 0.010 & -0.697733 & 0.010 & -0.000030 & -0.21 \\
\hline-3000 & -0.837247 & 0.010 & -0.837273 & 0.010 & -0.000032 & -0.22 \\
\hline-4000 & -1.116304 & 0.010 & -1.116343 & 0.010 & -0.000035 & -0.24 \\
\hline-5000 & -1.395363 & 0.010 & -1.395406 & 0.010 & -0.000031 & -0.22 \\
\hline
\end{tabular}

is the relative combined standard uncertainty ascribable to the traveling standards. $w_{\text {tra_bli }}$ is given by

$$
w_{\text {tra } \_, i}=\sqrt{w_{\text {rot } \_, i}{ }^{2}+w_{\text {rep } \_, i}{ }^{2}+w_{\text {lvr } \_, i}{ }^{2}+w_{\text {res } \_, i}{ }^{2}},
$$

where $w_{\text {rot } \_b}, w_{\text {rep_b } b}, w_{\mathrm{lvr} \__{-} b}$, and $w_{\text {res_b } b}$ are the relative standard uncertainties due to the reproducibility when changing the mounting position, the repeatability at a constant mounting position, the reproducibility when changing the lever length, and the resolution of the traveling standard, respectively. The measurement results showed good agreement with each other within the uncertainties, as shown in Figures 17, 18, and 19. Similarly, the comparison results for the TP-5N-1109 with the torque changed at intervals of $+5 \mathrm{~N} \cdot \mathrm{m}$ are shown in Figure 20 . The results for the TP-5N-1109 also showed good agreement within the uncertainties.

Table 10 shows the comparison results for the DmTS/10Nm. The relative expanded uncertainty, $W_{\mathrm{A}}$, is given by the following equation, which includes the influence of short-term drift:
$W_{\mathrm{A}, i}=k \cdot w_{\mathrm{A}, i}=k \sqrt{{w_{\mathrm{tsm} \_\mathrm{A}}}^{2}+w_{\text {tra } \_\mathrm{A}, i}^{2}}$,

$w_{\text {tra_A }, i}=\sqrt{w_{\text {rot_A_prej }}{ }^{2}+w_{\text {rep_A_prej }}{ }^{2}+w_{\text {lv__A_prej }}{ }^{2}+w_{\text {res_A_prej }}{ }^{2}+w_{\text {drf }, i}{ }^{2}}$,

where the subscript $A$ indicates the results measured using the $10-\mathrm{N} \cdot \mathrm{m}-\mathrm{DWTSM}$ and $w_{\text {drf }}$ is the relative standard uncertainty due to the short-term drift of the DmTS/10Nm. $w_{\text {drf }}$ is evaluated from the pre- and post-calibration results obtained using the $10-\mathrm{N} \cdot \mathrm{m}-\mathrm{DWTSM}$. In this Table, En numbers were less than one at all torque steps. Therefore, the equivalence of the two calibration methods involving changing the square drive direction of the DmTS/10Nm using the 10$\mathrm{N} \cdot \mathrm{m}-$ and $1-\mathrm{kN} \cdot \mathrm{m}-\mathrm{DW} T S M$ s was confirmed. Similarly, the comparison results for the TP-5N-1109 given in Table 11 demonstrate that $E n$ numbers were less than one when the torque was changed at intervals of $\pm 5 \mathrm{~N} \cdot \mathrm{m}$. Thus, the measurement results of the calibration method involving changing the TP-5N-1109 direction using the $10-\mathrm{N} \cdot \mathrm{m}-$ DWTSM were shown to be equivalent to those obtained using the $1-\mathrm{kN} \cdot \mathrm{m}-\mathrm{DWTSM}$. 


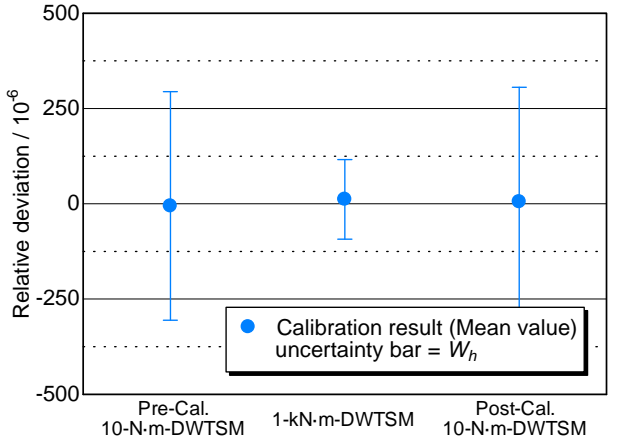

(a)

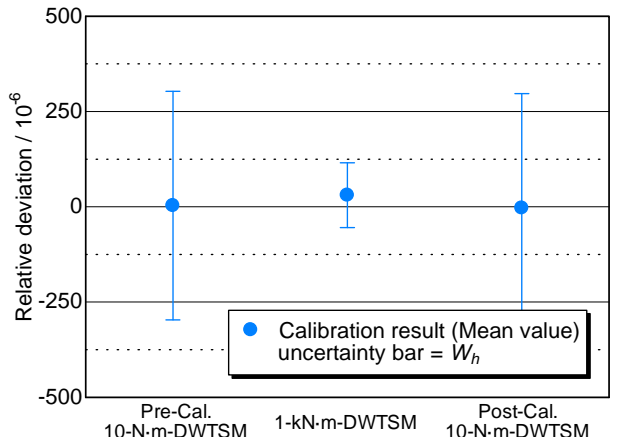

(b)

Figure 17. Results for the $\mathrm{DmTS} / 10 \mathrm{Nm}$ with torque changed at intervals of $+5 \mathrm{~N} \cdot \mathrm{m}$ in the (a) $\mathrm{CW}$ and (b) $\mathrm{CCW}$ directions.

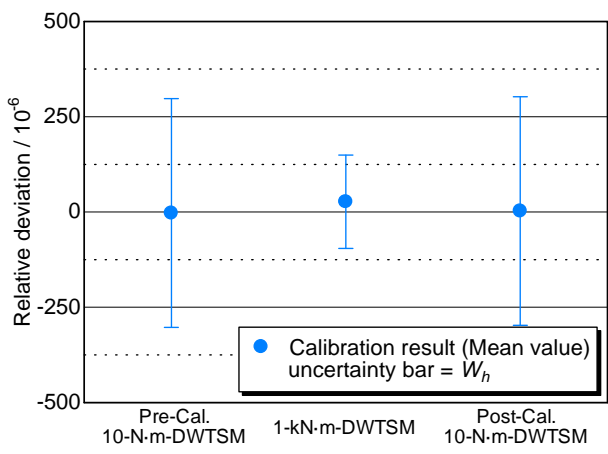

(a)

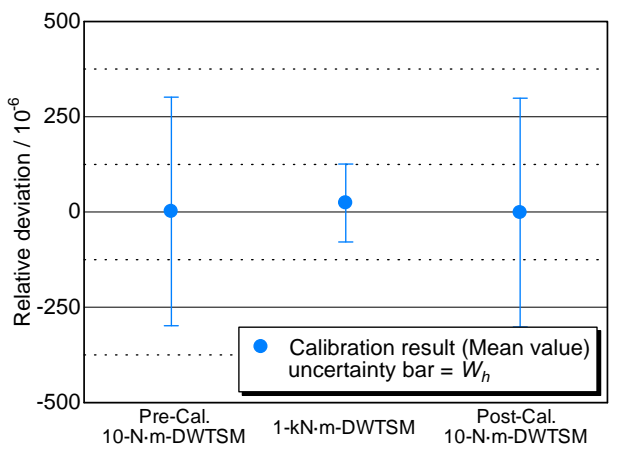

(b)

Figure 18. Results for the DmTS/10Nm with torque changed at intervals of $+10 \mathrm{~N} \cdot \mathrm{m}$ in the (a) $\mathrm{CW}$ and (b) $\mathrm{CCW}$ directions.

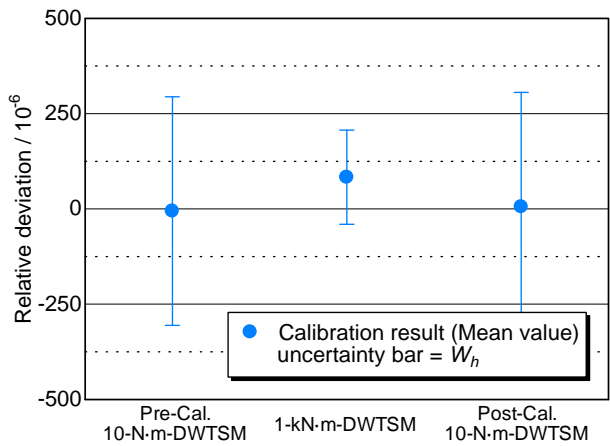

(a)

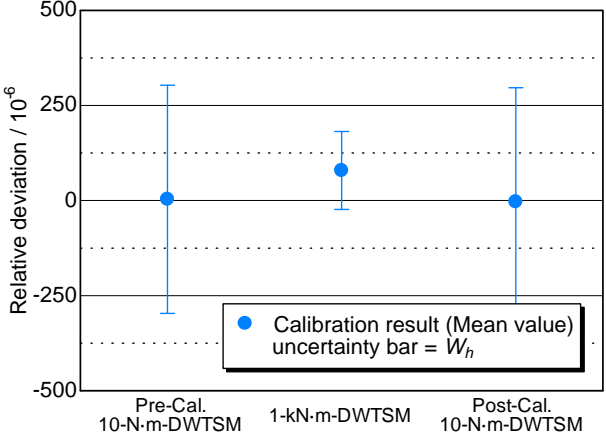

(b)

Figure 19. Results for the DmTS/10Nm with torque changed at intervals of $-5 \mathrm{~N} \cdot \mathrm{m}$ in the (a) $\mathrm{CW}$ and (b) $\mathrm{CCW}$ directions.

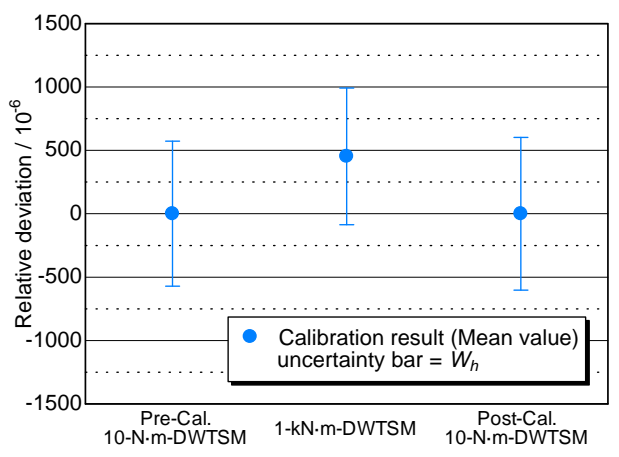

(a)

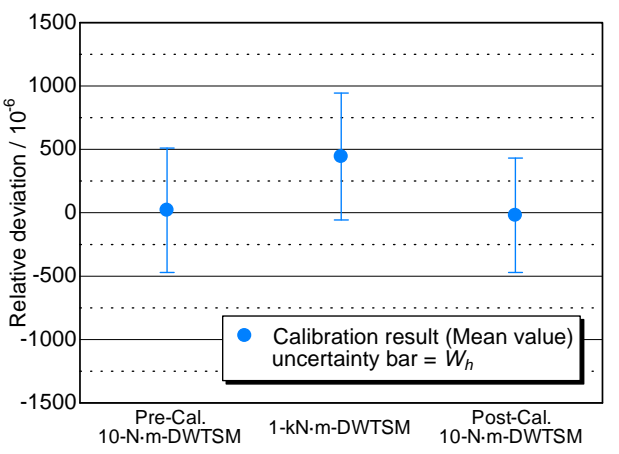

(b)

Figure 20. Results for the TP-5N-1109 with torque changed at intervals of $+5 \mathrm{~N} \cdot \mathrm{m}$ in the (a) CW and (b) CCW directions. 
Table 10. Comparison results for the DmTS/10Nm.

\begin{tabular}{|c|c|c|c|c|c|c|c|c|c|}
\hline \multirow[b]{2}{*}{ Direction } & \multirow[b]{2}{*}{$T / \mathrm{N} \cdot \mathrm{m}$} & \multirow[b]{2}{*}{ Inc. / Dec } & \multicolumn{2}{|c|}{ 10-N-m-DWTSM } & \multicolumn{2}{|c|}{ 1-kN·m-DWTSM } & \multirow[b]{2}{*}{$\left.W_{\text {drf }}{ }^{*}\right)$} & \multirow[b]{2}{*}{$R D^{*}$} & \multirow[b]{2}{*}{ En } \\
\hline & & & $\begin{array}{c}S_{\mathrm{A} \_ \text {ave }} \\
/(\mathrm{mV} / \mathrm{V})\end{array}$ & $\left.W_{A}^{*}\right)$ & $\begin{array}{c}S_{\mathrm{B}} \\
/(\mathrm{mV} / \mathrm{V})\end{array}$ & $W_{B}^{*}$ & & & \\
\hline \multirow{3}{*}{$\mathrm{CW}$} & -5 & Inc. & -1.000400 & 300 & -1.000431 & 85 & 1.9 & 30 & 0.10 \\
\hline & -10 & ----- & -2.000867 & 300 & -2.000914 & 102 & 0.9 & 24 & 0.07 \\
\hline & -5 & Dec. & -1.000343 & 300 & -1.000422 & 103 & 1.9 & 79 & 0.25 \\
\hline \multirow[t]{3}{*}{$C W$} & 5 & Inc. & 1.000426 & 300 & 1.000437 & 104 & 3.2 & 12 & 0.04 \\
\hline & 10 & ----- & 2.000932 & 300 & 2.000986 & 122 & 1.5 & 27 & 0.08 \\
\hline & 5 & Dec. & 1.000405 & 300 & 1.000488 & 124 & 3.3 & 83 & 0.26 \\
\hline
\end{tabular}

*) Relative values $\times 10^{-6}$

Table 11. Comparison results for the TP-5N-1109.

\begin{tabular}{|c|c|c|c|c|c|c|c|c|c|}
\hline \multirow[b]{2}{*}{ Direction } & \multirow[b]{2}{*}{$T / \mathrm{N} \cdot \mathrm{m}$} & \multirow[b]{2}{*}{ Inc. / Dec } & \multicolumn{2}{|c|}{ 10-N·m-DWTSM } & \multicolumn{2}{|c|}{ 1-kN·m-DWTSM } & \multirow[b]{2}{*}{$\left.W_{\mathrm{drf}}{ }^{*}\right)$} & \multirow[b]{2}{*}{$\left.R D^{*}\right)$} & \multirow[b]{2}{*}{ En } \\
\hline & & & $\begin{array}{c}S_{\mathrm{A} \_ \text {ave }} \\
/(\mathrm{mV} / \mathrm{V}) \\
\end{array}$ & $W_{A}^{*}$ & $\begin{array}{c}S_{\mathrm{B}} \\
/(\mathrm{mV} / \mathrm{V}) \\
\end{array}$ & $W_{\mathrm{B}}{ }^{*}$ & & & \\
\hline $\mathrm{CCW}$ & -5 & ----- & -1.155700 & 491 & -1.156213 & 500 & 11 & 443 & 0.63 \\
\hline $\mathrm{CW}$ & 5 & ----- & 1.155670 & 572 & 1.156193 & 539 & 0.2 & 453 & 0.58 \\
\hline
\end{tabular}

*) Relative values $\times 10^{-6}$

\section{CONCLUSION}

The RTW calibration procedure adopted by NMIJ is based on the JMIF-016 (TTSG-W102) technical guideline. The mounting position of an RTW was set to three directions $\left(0^{\circ}\right.$, $120^{\circ}$, and $240^{\circ}$; case 1 ) when it was calibrated using the 1 $\mathrm{kN} \cdot \mathrm{m}-$ and $20-\mathrm{kN} \cdot \mathrm{m}-\mathrm{DWTSMs}$. However, the mounting position was set to three different directions $\left(0^{\circ}, 90^{\circ}\right.$ and $270^{\circ}$; case 2) when an RTW was calibrated using the $10-N \cdot m-$ DWTSM. In this study, the effect of these differences in the RTW mounting positions on the calibration results was first investigated. Second, to confirm the equivalence of the capabilities of the $10-\mathrm{N} \cdot \mathrm{m}-$ and $1-\mathrm{kN} \cdot \mathrm{m}-\mathrm{DWTSMs}$ in the calibration of low-nominal capacity RTWs, an intra-laboratory comparison between the two TSMs was conducted using two high-accuracy RTWs. The following results were obtained.

(1) The calibration results obtained using the two sets of mounting position (cases 1 and 2) showed good agreement with each other within the uncertainties. Thus, although case 1 is recommended in principle, case 2 can also be adopted.

(2) Absolute values of the calibration results obtained in case 2 were slightly larger than those in case 1 under almost all calibration conditions.

(3) The uncertainties obtained in case 1 were nearly equal to or slightly larger than those obtained in case 2 .

(4) The RTW calibration capabilities of the $10-\mathrm{N} \cdot \mathrm{m}$ - and 1$\mathrm{kN} \cdot \mathrm{m}-\mathrm{DW} T S M s$ were found to be equivalent.

\section{REFERENCES}

[1] K. Ogushi, A. Nishino, K. Maeda and K. Ueda, "Range expanded expansion of the reference torque wrench calibration service to $5 \mathrm{kN} \mathrm{m}$ at NMIJ", Measurement 45 (2012) 1200-1209.

[2] A. Nishino, K. Ogushi and K. Ueda, "Development of a new small-rated-capacity reference torque wrench", Proc. APMF 2013, FM0003, Taipei, Taiwan, Nov. 2013.

[3] A. Nishino, K. Ogushi and K. Ueda, "Calibration of reference torque wrenches using a $10 \mathrm{~N}$ m deadweight torque standard machine", Measurement 61 (2015) 1-8.
[4] A. Nishino, K. Ogushi, K. Ueda, D. Röske and D. Mauersberger, "Bilateral Comparisons of Measurement Capabilities for the Calibration of Low Nominal Capacity Torque Measuring Devices between NMIJ and PTB in the Range from $0.1 \mathrm{~N} \cdot \mathrm{m}$ to $10 \mathrm{~N} \cdot \mathrm{m}$ using different procedures", Measurement 68 (2015) 32-41.

[5] D. Röske, "Final Report on the Torque Key Comparison CCM.T-K1 Measurand Torque: $0 \mathrm{~N} \cdot \mathrm{m}, 500 \mathrm{~N} \cdot \mathrm{m}, 1000 \mathrm{~N} \cdot \mathrm{m}$ ", 2009, Internet:

http://www.bipm.org/utils/common/pdf/final reports/M/TK1/CCM.T-K1.pdf.

[6] K. Ogushi, T. Ota, K. Ueda, D. Peschel and A. Brüge, "Interlaboratory Comparison of Reference Torque Wrench Calibration between NMIJ and PTB", Proc. XVIII IMEKO World Congress, CD-ROM, Rio de Janeiro, Brazil, Sept. 2006.

[7] K. Ogushi, A. Nishino, K. Maeda and K. Ueda, "Intra-laboratory comparison between calibration capabilities of reference torque wrench using two deadweight torque standard machines" (in Japanese), Proc. 27th Sensing forum of SICE, pp. 243-248, Kiryu, Japan, Sept. 2010.

[8] K. Ogushi, A. Nishino, K. Maeda, K. Ueda, A. Brüg and D. Röske, "Inter-laboratory Comparison of Reference Torque Wrench Calibration between NMIJ and PTB at the Range from $200 \mathrm{~N} \cdot \mathrm{m}$ to $2 \mathrm{kN} \cdot \mathrm{m}$ ", Proc. of XX IMEKO World Congress, ID- TC3-O-32, Busan, Republic of Korea, 2012.

[9] Torque Traceability Study Group ed., JMIF-016: Guideline for the calibration laboratory of reference torque wrenches (In Japanese), Japan Measuring Instrument Federation, 2004.

[10] K. Ohgushi, T. Ota and K. Ueda, "Load Dependency of the Moment-Arm Length in the Torque Standard Machine", Proc. XVII IMEKO World Congress, pp. 383-388, Dubrovnik, Croatia, June, 2003.

[11] K. Ohgushi, T. Ota and K. Ueda, "Uncertainty Evaluation of the $20 \mathrm{kN} \cdot \mathrm{m}$ Dead Weight Torque Standard Machine", Proc. the 19th Int. Conf. on Force, Mass \& Torque IMEKO TC3, CDROM, Cairo, Egypt, Feb. 2005.

[12] A. Nishino, K. Ogushi and K. Ueda, "Uncertainty evaluation of a $10 \mathrm{~N} \cdot \mathrm{m}$ dead weight torque standard machine and comparison with a $1 \mathrm{kN} \cdot \mathrm{m}$ dead weight torque standard machine", Measurement 49 (2014) 77-90.

[13] JCG209S11-05, JCSS Guideline on Uncertainty Estimation Torque Meters and Reference Torque Wrenches, International Accreditation Japan, National Institute of Testing and Evaluation, 2012 (in Japanese). 